\title{
CORRECTION
}

\section{A STANDARD INTRAVENOUS GLUCOSE TOLERANCE TEST}

In the paper entitled A Standard Intravenous Glucose Tolerance Test by Dr. T. Crawford, published in the last number of the Archives, the work of Dr. C. Wallace Ross was incorrectly quoted.

It was stated that he had used a watery solution of glucose for an intravenous glucose tolerance test, and the suggestion was made that the watery medium was responsible for some irregular and double-peaked curves which he had reported. Actually Dr. Ross used a solution of glucose in normal saline for the tests, so that the suggestion made cannot be supported.

The author of the paper regrets having allowed this error to arise. 